\title{
Inhibition of iNOS as a novel effective targeted therapy against triple-negative breast cancer
}

Sergio Granados-Principal', Yi Liu, Maria L Guevara², Elvin Blanco ${ }^{3}$, Dong Soon Choi', Wei Qian', Tejal Patel', Angel A Rodriguez ${ }^{1}$, Joseph Cusimano ${ }^{4}$, Heidi L Weiss ${ }^{5}$, Hong Zhao ${ }^{6}$, Melissa D Landis ${ }^{1}$, Bhuvanesh Dave ${ }^{1}$, Steven S Gross ${ }^{7}$ and Jenny C Chang ${ }^{1,6^{*}}$

\begin{abstract}
Introduction: Triple-negative breast cancer (TNBC) is an aggressive form of breast cancer with no effective targeted therapy. Inducible nitric oxide synthase (iNOS) is associated with poor survival in patients with breast cancer by increasing tumor aggressiveness. This work aimed to investigate the potential of iNOS inhibitors as a targeted therapy for TNBC. We hypothesized that inhibition of endogenous iNOS would decrease TNBC aggressiveness by reducing tumor initiation and metastasis through modulation of epithelial-mesenchymal transition (EMT)-inducing factors.

Methods: iNOS protein levels were determined in 83 human TNBC tissues and correlated with clinical outcome. Proliferation, mammosphere-forming efficiency, migration, and EMT transcription factors were assessed in vitro after iNOS inhibition. Endogenous iNOS targeting was evaluated as a potential therapy in TNBC mouse models.

Results: High endogenous iNOS expression was associated with worse prognosis in patients with TNBC by gene expression as well as immunohistochemical analysis. Selective iNOS (1400 W) and pan-NOS (L-NMMA and L-NAME) inhibitors diminished cell proliferation, cancer stem cell self-renewal, and cell migration in vitro, together with inhibition of EMT transcription factors (Snail, Slug, Twist1, and Zeb1). Impairment of hypoxia-inducible factor $1 \mathrm{a}$, endoplasmic reticulum stress (IRE1a/XBP1), and the crosstalk between activating transcription factor 3/activating transcription factor 4 and transforming growth factor $\beta$ was observed. iNOS inhibition significantly reduced tumor growth, the number of lung metastases, tumor initiation, and self-renewal.

Conclusions: Considering the effectiveness of L-NMMA in decreasing tumor growth and enhancing survival rate in TNBC, we propose a targeted therapeutic clinical trial by re-purposing the pan-NOS inhibitor L-NMMA, which has been extensively investigated for cardiogenic shock as an anti-cancer therapeutic.
\end{abstract}

\section{Introduction}

Triple-negative breast cancer (TNBC) is an aggressive and lethal form of cancer that lacks estrogen receptor alpha $(E R \alpha)$, progesterone, and human epidermal growth factor receptors with no approved targeted therapeutic options. Despite numerous advances, treatment resistance and metastasis are the main causes of death in patients with TNBC. Resistance to conventional treatment and onset of metastases may arise from a subpopulation of

\footnotetext{
* Correspondence: jcchang@houstonmethodist.org

'Methodist Cancer Center, Houston Methodist Hospital, 6445 Main Street, P21-34, Houston, TX 77030, USA

${ }^{6}$ Department of Systems Medicine and Bioengineering, Houston Methodist Research Institute, 6670 Bertner Avenue, Houston, TX 77030, USA Full list of author information is available at the end of the article
}

cancer stem cells (CSCs) with self-renewal and tumorinitiating capacities $[1,2]$. Thus, combinatorial treatments with conventional chemotherapy and anti-CSC therapies would be necessary to reduce tumor burden, recurrence, and metastasis to distant organs $[3,4]$.

Nitric oxide (NO) is a bioactive molecule that exhibits pleotropic effects within cancer cells and tumors, with concentration-dependent pro- and anti-tumor effects. $\mathrm{NO}$ is produced by three different nitric oxide synthase (NOS) isoforms: neuronal (nNOS/NOS1), inducible (iNOS/ NOS2), and endothelial (eNOS/NOS3) [5]. Increased iNOS expression has been found in breast cancer [6-9] and other different cancers such as lung [10], colon [11], melanoma [12], and glioblastoma [13]. Previous reports have demonstrated a correlation between high iNOS expression, 
aggressiveness, and poor prognosis in patients with breast cancer [6-9]. Increased iNOS expression has recently been postulated as a prognostic factor for reduced survival in patients with basal-like ER $\alpha$-negative breast cancer through the induction of interleukin-8 (IL-8), CD44, c-Myc [7] and partially due to the activation of the transcription factor Ets-1 [14]. Here, we hypothesize that enhanced endogenous iNOS expression drives poor patient survival by promoting tumor relapse and metastases through modulation of CSC self-renewal properties and tumor cell migration. We further hypothesize that, in combination with conventional chemotherapy, the inhibition of endogenous iNOS would reduce the aggressiveness of residual TNBC cells and mesenchymal features and the number of metastases to distant organs, thus improving survival of patients with TNBC. We studied the inhibition of iNOS with different small-molecule inhibitors: the selective iNOS inhibitor $1400 \mathrm{~W}$ and two pan-NOS inhibitors: L-NMMA and L-NAME. L-NMMA has been extensively studied in hundreds of patients for cardiogenic shock [15] and, if efficacious, would enable immediate translation into clinical trials without the need of extensive preclinical testing.

\section{Methods \\ Reagents}

$\mathrm{N}$-[[3-(aminomethyl)phenyl]methyl]-ethanimidamide $(1400 \mathrm{~W})$ and N5-[imino(nitroamino)methyl]-L-ornithine methyl ester (L-NAME) were purchased from Cayman Chemical (Ann Arbor, MI, USA). Tilarginine ( $\mathrm{N}^{\mathrm{G}}$ Monomethyl-L-arginine) (L-NMMA) was from Santa Cruz Biotechnology (Dallas, TX, USA) and kindly supplied by (Arginox Pharmaceuticals, Redwood City, CA, USA). Tunicamycin and recombinant human TGF- $\beta 1$ were obtained from Abcam (Cambridge, UK) and PeproTech (Rocky Hill, NJ, USA), respectively. iNOS (N-20), eNOS (C-20), nNOS (R-20), Twist1 (L-21), Twist1 (2C1a), ATF3 (C-19), and CREB-2 (C-20) antibodies were from Santa Cruz Biotechnology. Antibodies Snail (C15D3), Slug (C19G7), TCF8/Zeb1 (D80D3), PERK (C33E10), TGF $\beta$, phospho-Smad2/3 (D6G10), Smad2/3, IRE1 $\alpha$ (14C10), phospho-PERK (16 F8), PERK (C33E10), phospho-eIF2 $\alpha$ (119A11), eIF2 $\alpha, \beta$-Actin, anti-rabbit, and anti-mouse IgG were obtained from Cell Signaling Technology (Danvers, MA, USA). Hypoxia-inducible factor $1 \alpha$ (HIF1 $\alpha)$ (EP1215Y) was from Abcam.

\section{Oncomine gene expression data analysis}

Relative levels of NOS2 mRNA expression in human TNBC were investigated by Oncomine Cancer Microarray database analysis [16] of The Cancer Genome Atlas (TCGA) database $(n=593)$. Patient survival analysis of two different gene expression data sets was obtained $[17,18]$.

\section{Cell culture}

Mesenchymal-like TNBC cell lines MDA-MB-231 and SUM159 were purchased from American Type Culture Collection (Manassas, VA, USA) and Asterand Bioscience (Detroit, MI, USA), respectively. These cell lines were chosen on the basis of their high expression of epithelialmesenchymal transition (EMT) markers, metastatic properties, percentage of $\mathrm{CD} 44^{+} / \mathrm{CD} 24^{-}$cells, iNOS protein levels, similar protein levels of iNOS downstream targets, and similar production of total NO (data not shown). Cells were grown in Dulbecco's modified Eagle's medium (DMEM) (Gibco, Life Technologies, Grand Island, NY 14072 USA) supplemented with $10 \%$ fetal bovine serum and $1 \%$ antibiotic-antimycotic. Unless otherwise specified, cells were treated daily with $1400 \mathrm{~W}(0.1,1,10,100 \mu \mathrm{M}$; 1, 2, $4 \mathrm{mM})$, L-NMMA $(0.1,1,10,100 \mu \mathrm{M} ; 1,2,4 \mathrm{mM})$, or L-NAME $(0.1,1,10,100 \mu \mathrm{M} ; 1,2,5 \mathrm{mM})$ for 96 hours.

For mammosphere (MS) formation (MSFE), cells were cultured for 96 hours under treatment in $0.5 \%$ methylcellulose and MammoCult basal medium (StemCell Technologies, Vancouver, BC, Canada) supplemented with $10 \%$ proliferation supplements, $4 \mu \mathrm{g} / \mathrm{mL}$ heparin, and $0.48 \mu \mathrm{g} / \mathrm{mL}$ hydrocortisone. Primary MSs were scanned and counted with GelCount (Oxford Optronix, Abingdon, UK). Secondary MSs were grown in the absence of treatment. For the mouse model of lung metastasis, MDA-MB-231 cells were transfected with a luciferase/ GFP-based dual-reporter plasmid and stable clones (MDAMB-231 L/G) selected with blasticidin (InvivoGen, San Diego, CA, USA).

\section{Cell proliferation assay}

Proliferation of SUM159 and MDA-MB-231 was determined by adding premixed WST-1 reagent (Clontech, Mountain View, CA, USA). For transient knockdown in SUM159 and MDA-MB-231 cells (500 cells per well), proliferation was determined after 72 hours of transfection.

\section{Wound healing assay}

Confluent cells were treated in starvation conditions (1\% serum) for 72 hours. Medium was changed by regular growth medium in the presence of inhibitors for 24 hours more. For transient knockdown, cells were transfected for 72 hours in growth media. A 'wound' was then created in the cell monolayer with a $100-\mu \mathrm{L}$ pipette tip. Images were taken at 0 and 14 hours. Data were replicated in three independent experiments.

\section{RNA interference experiments}

SUM159 and MDA-MB-231 cells were transiently transfected with Scrambled siRNA, siRNA1, or siRNA2 (100 nM) (Silencer Select; Ambion, Life Technologies, Grand Island, NY 14072 USA) for 96 hours using Lipofectamine RNAiMAX (Invitrogen, Life Technologies, Grand Island, 
NY 14072 USA) in accordance with the instructions of the manufacturer. GIPZ lentiviral NOS2 (shRNA1 V3LHS_360691) and empty vector shRNAs were purchased from Thermo Fisher Scientific. MDA-MB-231 cells were transduced with lentiviral particles and selected with puromycin. Cells were then harvested and plated for immunocytochemistry of iNOS.

\section{Nitric oxide production}

Cells were treated with L-NMMA or $1400 \mathrm{~W}$ for 24 hours in phenol red- and serum-free DMEM. Aliquots of cell culture supernatant were taken at $0,0.5,2,6$, and 24 hours for total NO production with the nitrate/nitrite fluorometric assay kit (Cayman Chemical) in accordance with the instructions of the manufacturer.

\section{Western blot}

Whole cell lysates were made in 1X lysis buffer (Cell Signaling Technology) and $1 \mathrm{X}$ protease/phosphatase inhibitor cocktail (Thermo Scientific). Samples (30 $\mu \mathrm{g}$ protein) were boiled in sample buffer (Thermo Scientific) containing $\beta$-mercaptoethanol (Sigma-Aldrich, St. Louis, MO, USA) and subjected to SDS-PAGE electrophoresis in $4 \%$ to $20 \%$ polyacrylamide gels (Bio-Rad, Hercules, CA, USA). Proteins were transferred onto nitrocellulose membranes (Bio-Rad). Membranes were incubated overnight at $4{ }^{\circ} \mathrm{C}$ with primary antibodies $(1: 1,000)$ and the appropriate secondary antibodies for 1 hour $(1: 2,000)$. Protein bands were developed in autoradiography films (Denville Scientific Inc., South Plainfield, NJ, USA).

\section{RT-PCR analysis of spliced XBP1}

cDNA was synthetized from total RNA and subsequently amplified by polymerase chain reaction (PCR). The primers were XBP1 (5' -GGGTCCAAGTTGTCCAGAATGC-3' and $5^{\prime}$-TTACGAGAGAAAACTCATGGC-3') and $\beta$-Actin (5'-CTGGAACGGTGAAGGTGACA-3' and $5^{\prime}$-AAG GGACTTCCTGTAACAATGCA-3'). PCR conditions were 1 cycle at $95^{\circ} \mathrm{C}$ for 5 minutes, 25 cycles of 30 seconds at $95^{\circ} \mathrm{C}, 1$ minute at $50^{\circ} \mathrm{C}$, and 1 minute at $68^{\circ} \mathrm{C}$, followed by 1 cycle at $68^{\circ} \mathrm{C}$ for 5 minutes. cDNA amplicons were resolved in $2 \%$ agarose.

\section{Immunohistochemistry}

After antigen retrieval (Tris-Cl, $\mathrm{pH}$ 9.0), paraffin-embedded sections of human patient samples and xenograft tumors were incubated for 1 hour at room temperature with iNOS (1:50) (Novus Biologicals, Littleton, CO, USA), Ki67 (1:100) (Abcam), and cleaved caspase-3 (1:50) (Cell Signaling Technology) antibodies. The iNOS score method was as follows: intensity (0 to 3): negative, weak, moderate, strong; distribution ( 0 to 4 ): $<10 \%, 10 \%$ to $30 \%,>30 \%$ to $50 \%,>50 \%$ to $80 \%,>80 \%$. Total score can be divided into four groups: negative ( 0 or 1$)$, weak ( 2 or 3 ), moderate
(4 or 5), and strong (6 or 7) as previously reported [7]. MDA-MB-231 cells transfected either with NOS2-directed shRNA (shRNA1) or empty vector were used as negative and positive control of iNOS staining, respectively.

\section{Animal studies}

Either MDA-MB-231 or SUM159 cells $\left(3 \times 10^{6}\right)$ were injected in the right mammary fat pad of female severe combined immunodeficiency (SCID) Beige mice. Once the tumors reached 150 to $200 \mathrm{~mm}^{3}$, the mice were randomly assigned as follows ( $\mathrm{n}=10$ per group): (1) vehicle (saline, intraperitoneal, or i.p.), (2) L-NMMA (either $80 \mathrm{mg} / \mathrm{kg}$ or $200 \mathrm{mg} / \mathrm{kg}$, i.p., daily), (3) docetaxel (20 mg/kg), and (4) combo (L-NMMA and docetaxel). For the lung metastases-preventing study, MDA-MB-231 L/G cells were implanted as described above. The mice were randomly assigned, and treatments started 48 hours after cell injection ( $\mathrm{n}=5$ per group): (1) vehicle (saline, i.p.) and (2) L-NAME (80 mg/kg, i.p., daily for 35 days). Lungs were removed and incubated in cold complete DMEM containing $50 \mu \mathrm{M}$ luciferin for 10 minutes. Luminescent cancer cells were detected with an IVIS-200 in vivo imaging system (PerkinElmer, Waltham, MA, USA). The clinically relevant dose regimen consisted on two cycles of docetaxel $(20 \mathrm{mg} / \mathrm{kg}$, i.p., on day 0), L-NMMA ( $400 \mathrm{mg} / \mathrm{kg}$ on day 1 , and $200 \mathrm{mg} / \mathrm{kg}$ for 4 additional days by oral gavage), and amlodipine on day $0(10 \mathrm{mg} / \mathrm{kg}$, i.p., daily, for 6 days). Docetaxel alone as well as saline (i.p.) + sterile water (oral gavage) were used as controls.

MS formation and limiting dilution assay (LDA) were assayed as previously described [4]. All animal procedures and experimental protocols were approved by the Houston Methodist Research Institute Animal Care and Use Review Office that ensured adherence to the National Institutes of Health Guide for the Care and Use of Laboratory Animals.

\section{Metabolite profiling by liquid chromatography-tandem mass spectrometry}

Xenograft tissue as well as plasma samples were prepared as previously described [19]. L-NMMA (200 mg/kg) was orally administered by gavage to female SCID Beige mice $(\mathrm{n}=5)$. Blood was drawn before (baseline, 0 hours) and after (0.5, 2, 12, and 24 hours) L-NMMA administration. Ratiometric quantification of methylarginine (L-NMMA) and citrulline was determined as ion abundance levels in plasma and tumor tissue [19].

\section{Blood pressure}

Blood pressure (BP) was measured in 15 female SCID Beige mice for 3 days (basal BP) and subsequently treated with one cycle of the clinically relevant dose regimen $(\mathrm{n}=5$ per group). The average daily BP was determined by averaging the last 10 of $20 \mathrm{BP}$ measurements for the 
last three consecutive days of the cycle treatment using a computerized tail cuff monitor (BP-2000 Series II; Visitech Systems, Napa Place, Apex, NC, USA).

\section{Statistical analysis}

All data were analyzed by using GraphPad Prism (GraphPad Software, La Jolla, CA, USA). Data are presented as mean \pm standard error of the mean. Statistical significance between two groups was analyzed by two-tailed Student's $t$ test. Experiments with more than three groups were analyzed with one-way analysis of variance (ANOVA) and Bonferroni's post hoc test. Statistical analysis of tumor volume was assessed by twoway ANOVA and Bonferroni's post hoc test. Fisher's exact test was used to determine significant differences in LDA. Survival proportions were assessed by using a Kaplan-Meier method and further analyzed with either Wilcoxon or log-rank test. Proliferation, MSFE, migration index, and Ki67 staining are normalized to the vehicle group (100\%). A $P$ value of less than 0.05 was considered significant.

\section{Results}

Enhanced iNOS expression correlates with poor patient survival in invasive TNBC

iNOS has been described to be mediator of metastasis in different cancer types [20,21]. Elevated iNOS expression has been linked to poor survival in patients with ER $\alpha$-negative breast cancer [7]. We hypothesized that enhanced iNOS expression in TNBC correlates with poor patient survival and metastases. Oncomine Cancer Microarray database analysis of NOS2 expression in TCGA breast database showed higher NOS2 expression in invasive TNBC $(\mathrm{n}=46)$ versus non-TNBC $(\mathrm{n}=250)$ (fold change $1.425, P=3.85 \times 10^{-5}$ ) (Figure 1A). Patient survival analysis demonstrated a correlation between increased NOS2 expression and worse survival at 5 years in patients with invasive ductal breast carcinoma $(\mathrm{n}=79)$ (fold change 1.275, $P=0.037)$ (Figure 1B). We further examined whether NOS2 expression correlates with worse survival in two additional databases of TNBC. Analysis of Van de Vijver ( $\mathrm{n}=69$ samples) [17] and Curtis $(\mathrm{n}=260$ samples) [18] databases confirmed that high NOS2 expression was associated with poor survival in patients with TNBC (Figure 1C and D).

Next, we examined iNOS protein expression by immunohistochemistry in 83 surgically resected TNBC primary breast cancer samples, and correlated expression with known patient outcome. iNOS was primarily cytoplasmic, but some cells exhibited both cytoplasmic and nuclear localization (Figure 1E). Overall score showed that iNOS levels were weak to moderate (score 3 or 4) in 14 samples (16.9\%) (Figure 1E, score 3 or 4), moderate to strong (score 5 or 6 ) in 50 samples (60.2\%) (Figure 1E), and strong (score 7) in 19 specimens (22.9\%) (Figure 1E).
This stratification was used to analyze the correlation of iNOS expression and patient survival by using the Kaplan-Meier analysis. We confirmed that enhanced iNOS protein levels were associated with worse patient survival when compared with low iNOS expression $(P=0.05)$ (Figure 1F). These results demonstrate that increased iNOS by mRNA and protein expression in invasive TNBC is associated with poor patient survival.

\section{Inhibition of iNOS decreases cell proliferation, migration,} and mammosphere formation of TNBC cells

High concentrations of $1400 \mathrm{~W}(1,2$, and $4 \mathrm{mM})$ significantly decreased proliferation in both cell lines (Figure 2A). Similar results were observed for L-NAME (Additional file 1: Figure S1A). L-NMMA at the highest concentration $(4 \mathrm{mM})$ showed anti-proliferative activity in both cell lines (Figure 2B). Resistance to treatment and metastasis may arise from a subpopulation of CSCs within a heterogeneous primary cancer [22,23]. iNOS inhibition decreased primary MSs in both cell lines (Figure 2C; Additional file 1: Figure S1B; Additional file 2: Figure S2A; and Additional file 3: Figure S3A). We found reduced secondary MS in both cell lines for all the inhibitors tested (Figure 2D; Additional file 1: Figure S1C; Additional file 2: Figures S2B; and Additional file 3: Figure S3B). We show enhanced iNOS expression in invasive TNBC (Figure 1A); we then investigated the role of iNOS in cell migration. Selective iNOS inhibition with $1400 \mathrm{~W}$ caused a marked dose-dependent decrease in migration in both cell lines (Figure 2E and Additional file 1: Figure S1D). L-NMMAtreated cells showed reduction in migration capacity (Figure 2F and Additional file 1: Figure S1E). Similar results were found for L-NAME (Additional file 4: Figure S4A). These results were further confirmed in siRNA-mediated iNOS (NOS2) knockdown MDA-MB-231 (Figure 3A-C) and SUM159 cells (Additional file 5: Figure S5A, B, and $\mathrm{C}$ ). Collectively, the results indicate that basal levels of iNOS have a major role in CSC self-renewal and migrating properties of TNBC cell lines and a less pronounced effect on proliferation.

\section{Suppression of endogenous iNOS could impair EMT and cell migration by impairing HIF1a and the endoplasmic reticulum stress/TGF $\beta /$ AFT4/ATF3 crosstalk}

EMT is evoked during tumor invasion and metastasis $[3,24]$. We examined the impact on NOS isoforms (iNOS, eNOS, and nNOS) after either selective or pan-inhibition (Figure 3D and Additional file 4: Figure S4B, C, and F). Selective iNOS blockade with $1400 \mathrm{~W}$ caused a reduction in protein levels of the EMT transcription factors Snail, Slug, and Twist1 (Figure 3D and Additional file 4: Figure S4D). Zeb1 protein levels were decreased at millimolar concentrations (Figure 3D). Though less consistent, similar results were found for the pan-NOS inhibitors 
A

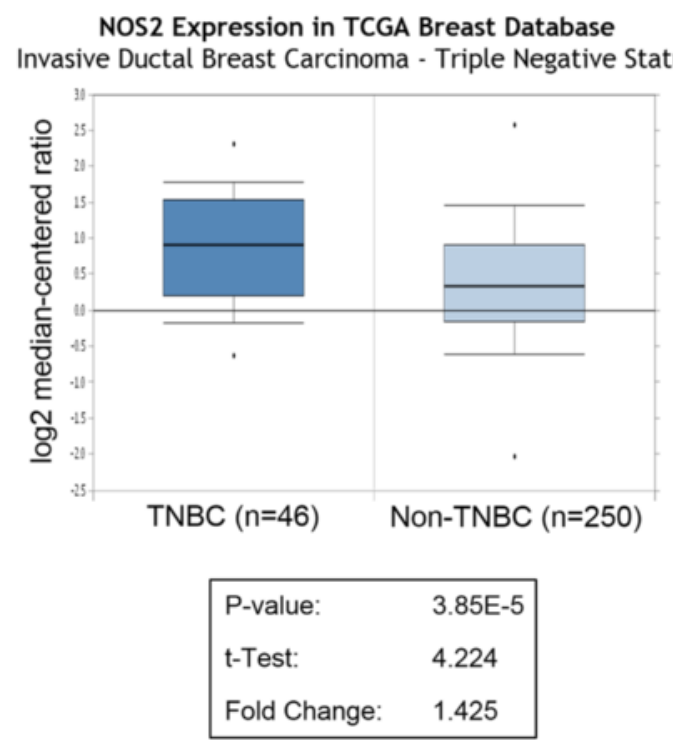

C
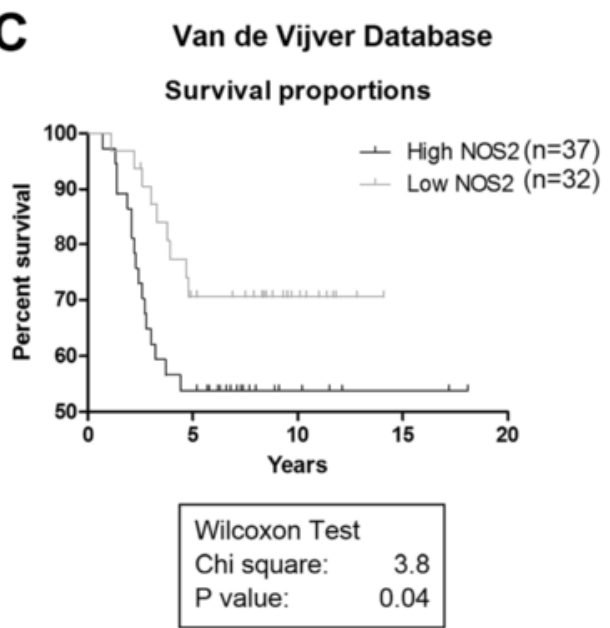

E

3

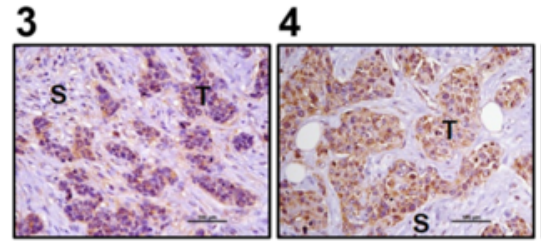

6

7

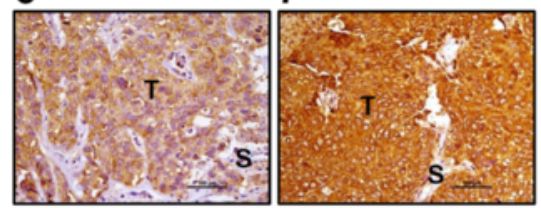
5
B

NOS2 Expression in TCGA Breast Database Invasive Ductal Breast Carcinoma - Dead at 5 Years

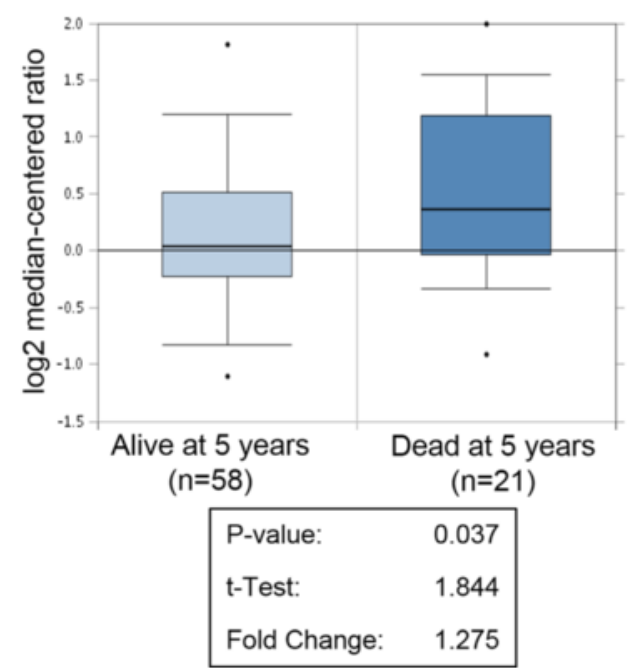

D

\section{Curtis Database}

Survival proportions

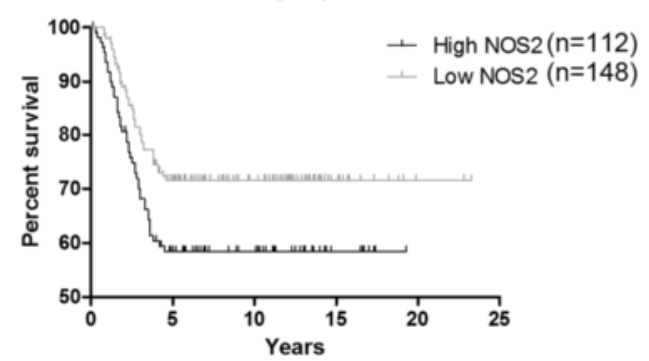

$\mathbf{F}$
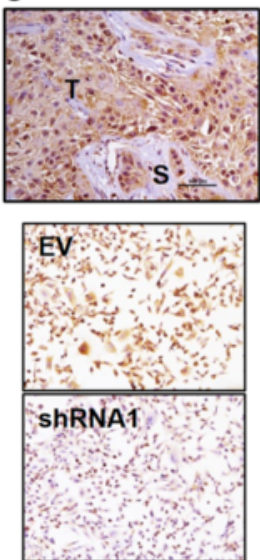
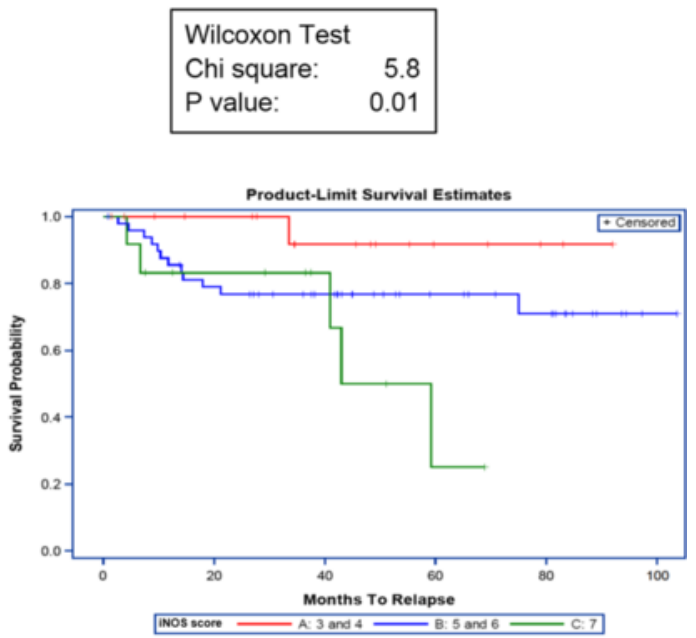

Figure 1 (See legend on next page.) 
(See figure on previous page.)

Figure 1 Enhanced nitric oxide synthase 2 (NOS2) expression correlates with poor patient survival in invasive triple-negative breast cancer (TNBC). (A) Higher NOS2 mRNA expression in invasive TNBC versus non-TNBC $\left(P=3.85 \times 10^{-5}\right)$. (B) High NOS2 expression correlates with death at 5 years in invasive breast carcinoma $(P=0.037)$. Kaplan-Meier survival analyses in $(\mathbf{C})$ Van de Vijver $(n=69 ; P=0.04)$ and $(\mathbf{D})$ Curtis $(n=260$; $P=0.01$ ) breast databases show that high NOS2 expression correlates with worse overall survival of patients with TNBC. (E) Immunohistochemical analysis of TNBC human samples for inducible nitric oxide synthase (iNOS) protein expression. Weak-to-moderate (3 or 4), moderate-to-strong (5 or 6), and strong (7) were the cutoffs established for further analysis of survival. Several samples showed expression in both tumor (T) and stromal (S) cells (original optical objective: 20X). MDA-MB-231 cells transfected with either NOS2-directed shRNA (shRNA1) or empty vector (EV) were used as negative and positive control of iNOS staining, respectively (original optical objective: 10X). Counterstain: hematoxylin. (F) Increased iNOS expression is associated with less patient sunvival when compared with low iNOS expression. Kaplan-Meier survival analysis of TNBC human patient samples $(n=83)(P=0.05)$. shRNA1, small hairpin RNA 1; TCGA, The Cancer Genome Atlas.

(Additional file 4: Figure S4E and F). iNOS knockdown with siRNA correlated with a decrease of Zeb1 and Twist1 protein levels in both cell lines (Figure 3E). Overall, these data suggest that selective iNOS inhibition efficiently decreases migration of TNBC cell lines, and this is consistently correlated with a decrease of EMT transcription factors.

Different pathways are responsible for inducing EMT and metastasis of tumor cells; among them, NO is a common denominator of HIF1 $\alpha$ and endoplasmic reticulum (ER) stress [25-27]. Our findings indicate that selective iNOS inhibition resulted in a dose-dependent decrease in hypoxia (HIF1 $\alpha$ ) (Figure 3F and Additional file 4: Figure S4G) and the ER stress markers IRE1 $\alpha$ /splicedXBP1 (Figure 3F and Additional file 5: Figure S5E) and ATF4 (activating transcription factor 4) in both cell lines (splicedXBP1 was not detected in SUM159 cells; data not shown) (Figure 3F). Functional protein-protein interaction analysis unveiled a link between iNOS and TGF $\beta 1$ (Additional file 5: Figure S5D). We confirmed that $1400 \mathrm{~W}$ is able to inhibit transforming growth factor $\beta$ (TGF $\beta$ ) signaling in the absence (Figure 3G) and presence of recombinant TGF $\beta 1$ (Additional file 5: Figure S5F) through an undetermined mechanism. Additional protein-protein interaction analyses showed an interaction between ATF4 and ATF3 (activating transcription factor 3) (Additional file 5: Figure S5D), both activating transcription factors that interact with TGF $\beta[28,29]$. We confirmed the crosstalk between ER stress through ATF4/ATF3 and TGF 3 (Additional file 5: Figure S5G); similarly, recombinant TGF $\beta 1$ induced the PERK/eIF2 $\alpha /$ ATF4/ATF3 axis (Figure 3H). Our results show that co-treatment of the iNOS inhibitor $1400 \mathrm{~W}$ and recombinant TGF $\beta 1$ (pretreatment for 7 days) for 24 hours was able to inhibit the stimulation of ATF4 and ATF3 protein levels by TGF $\beta 1$ independently of the PERK/eIF $2 \alpha$ pathway. This result was further confirmed in siRNAmediated iNOS knockdown cells (Figure 3I). Overall, our data demonstrate that iNOS inhibition could impair EMT and tumor cell migration by impairing ER stress (IRE1 $\alpha / \mathrm{XBP} 1)$ and the crosstalk between ATF4, ATF3, and TGF $\beta$.
iNOS inhibition reduces tumor growth and tumor-initiating capacity and prevents lung metastases in mouse models of TNBC

Considering our in vitro data, we next investigated whether L-NAME was able to prevent tumor initiation and metastasis of MDA-MB-231 L/G cells in mice. L-NAME significantly reduced tumor growth $(P=0.001)$ (Figure $4 \mathrm{~A})$ as well as primary MS (Figure 4B). Additionally, tumorinitiating capacity of CSCs was assessed with LDA. All of the animals of the vehicle group developed tumors, but treatment with L-NAME yielded 3/5 tumors at 1.5 weeks with $5 \times 10^{5}$ cells. The same results were observed in the vehicle group at 2.5 weeks with $1 \times 10^{5}$ cells compared with the L-NAME-treated group $(0 / 5$ tumors $)(P<0.05)$ (Figure 4D). Ex vivo imaging of lungs in the presence of luciferin showed higher fluorescence in the vehicle group compared with the L-NAME group (Figure 4C). These results suggest that iNOS inhibition with daily L-NAME may prevent metastasis to lungs in a TNBC mouse model.

To translate our results into future clinical trials, we used the pan-NOS inhibitor L-NMMA for further study. This is the first report using this drug re-purposed for this indication, with a paucity of data on the effective preclinical dose as an anti-cancer therapeutic. Thus, daily injections of $80 \mathrm{mg} / \mathrm{kg}$ L-NMMA were first given to SUM159 xenograft-bearing mice alone or in combination with docetaxel. After 10 days, no differential effect was observed between groups, and the daily dose was increased to $200 \mathrm{mg} / \mathrm{kg}$. The tumor growth was efficiently blocked by L-NMMA administered alone or in combination with docetaxel (Additional file 6: Figure S6A). Higher proliferating rate (Ki67) in the vehicle and chemotherapy groups compared with the L-NMMA and combination groups (Additional file 6: Figure S6B and C) was observed. L-NMMA efficiently blocked the docetaxelenhanced MSFE (Additional file 6: Figure S6D). LDA showed that the docetaxel and combination groups exhibited $12 / 12$ and $6 / 12$ tumors, respectively, at 7 weeks with $5 \times 10^{4}$ cells. At week 9, we observed significant reduction in tumor-initiating capacity as different groups with $2 \times 10^{4}$ cells yielded $3 / 12$ and $0 / 12$ tumors in docetaxel 
A

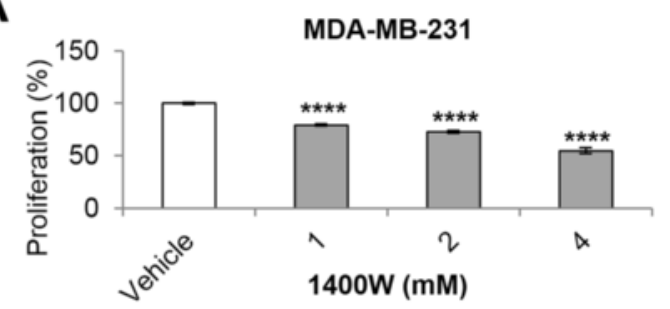

B

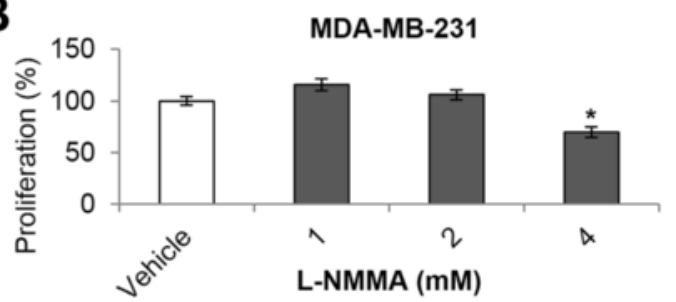

C

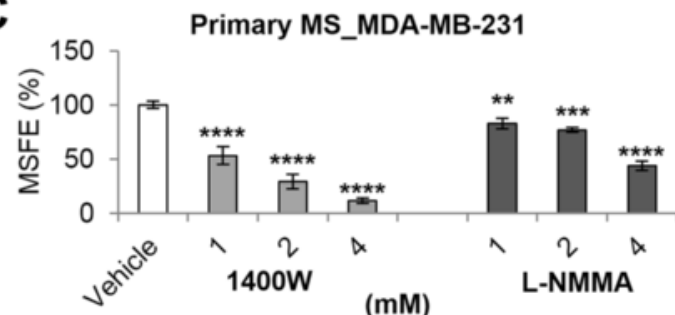

D

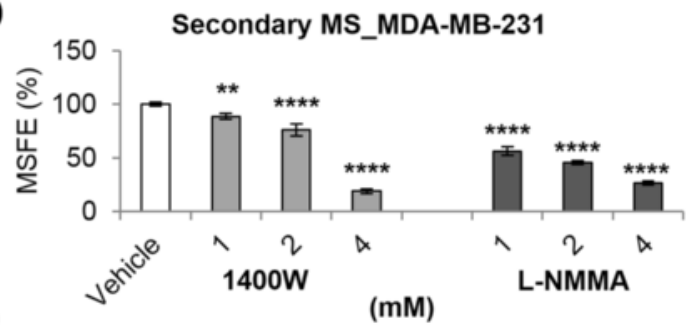

E

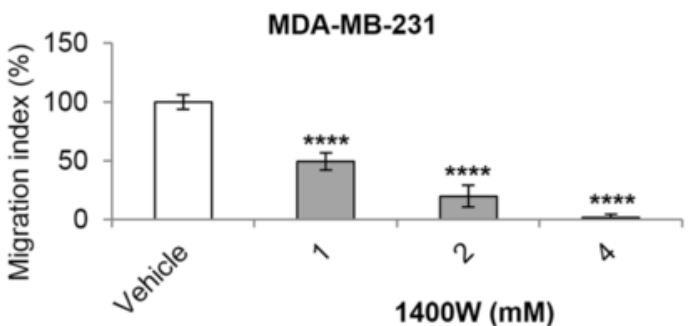

$\mathbf{F}$

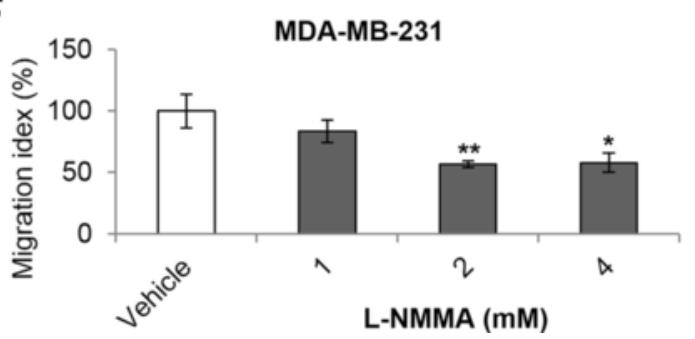

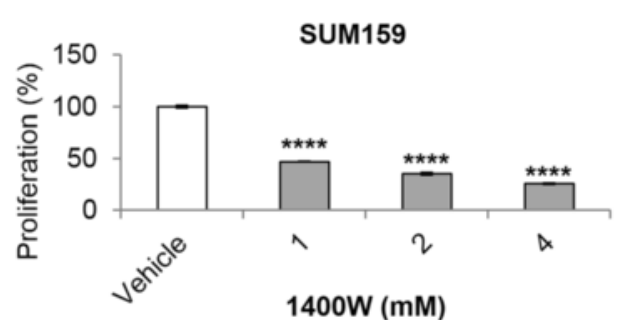

SUM159

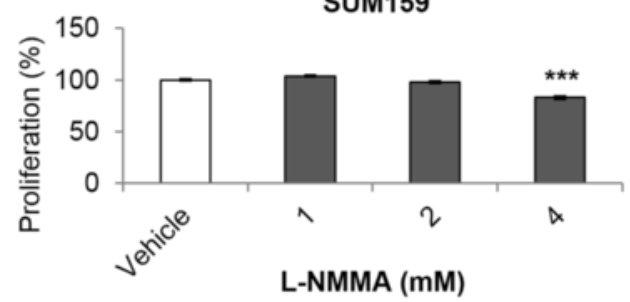

Primary MS_SUM159

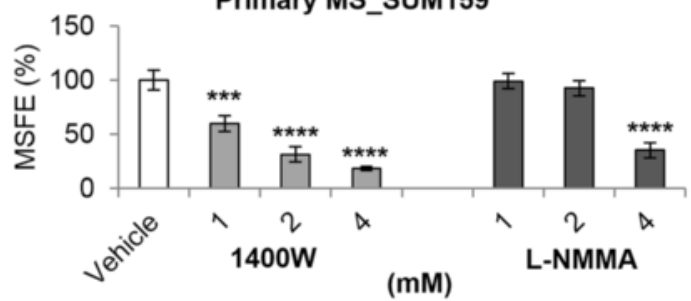

Secondary MS_SUM159

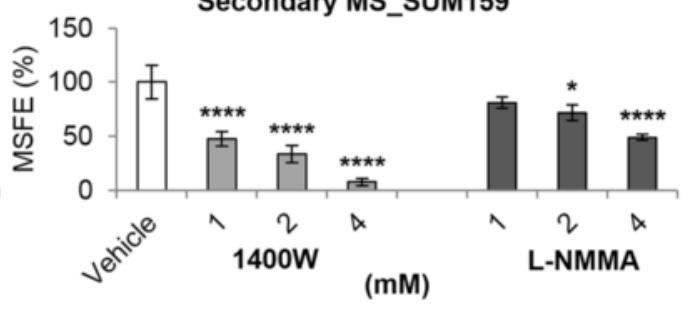

SUM159

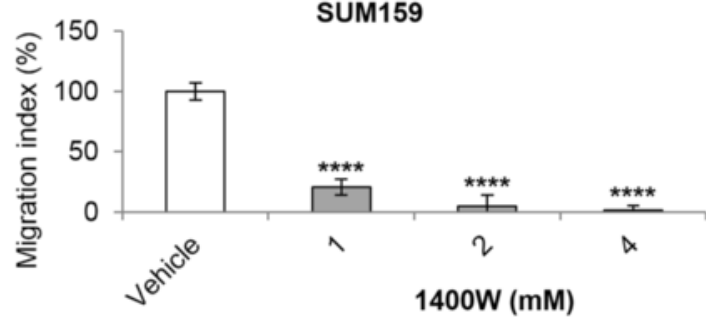

SUM159

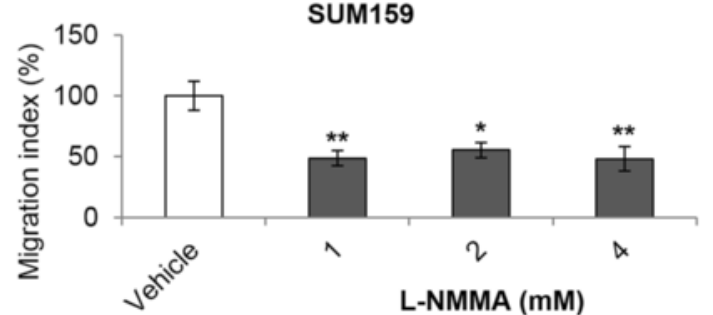

Figure 2 Effects of inducible nitric oxide synthase (iNOS) inhibitors on tumor cell proliferation, migration, and mammosphere formation in triple-negative breast cancer (TNBC) cell lines. Proliferation (A, B) and primary (C) and (D) secondary mammosphere, and migration index of MDA-MB-231 and SUM159 cell lines treated with $1400 \mathrm{~W}$ (E) and L-NMMA (F) for 96 hours. Results were

normalized to vehicle. Data are presented as mean \pm standard error of the mean. ${ }^{*} P<0.05,{ }^{* *} P<0.01,{ }^{* * *} P<0.001,{ }^{* * *} P<0.0001 .1400 \mathrm{~W}$, $\mathrm{N}$-[[3-(aminomethyl)phenyl]methyl]-ethanimidamide; L-NMMA, NG-monomethyl-L-arginine; MSFE, mammosphere-forming efficiency. 


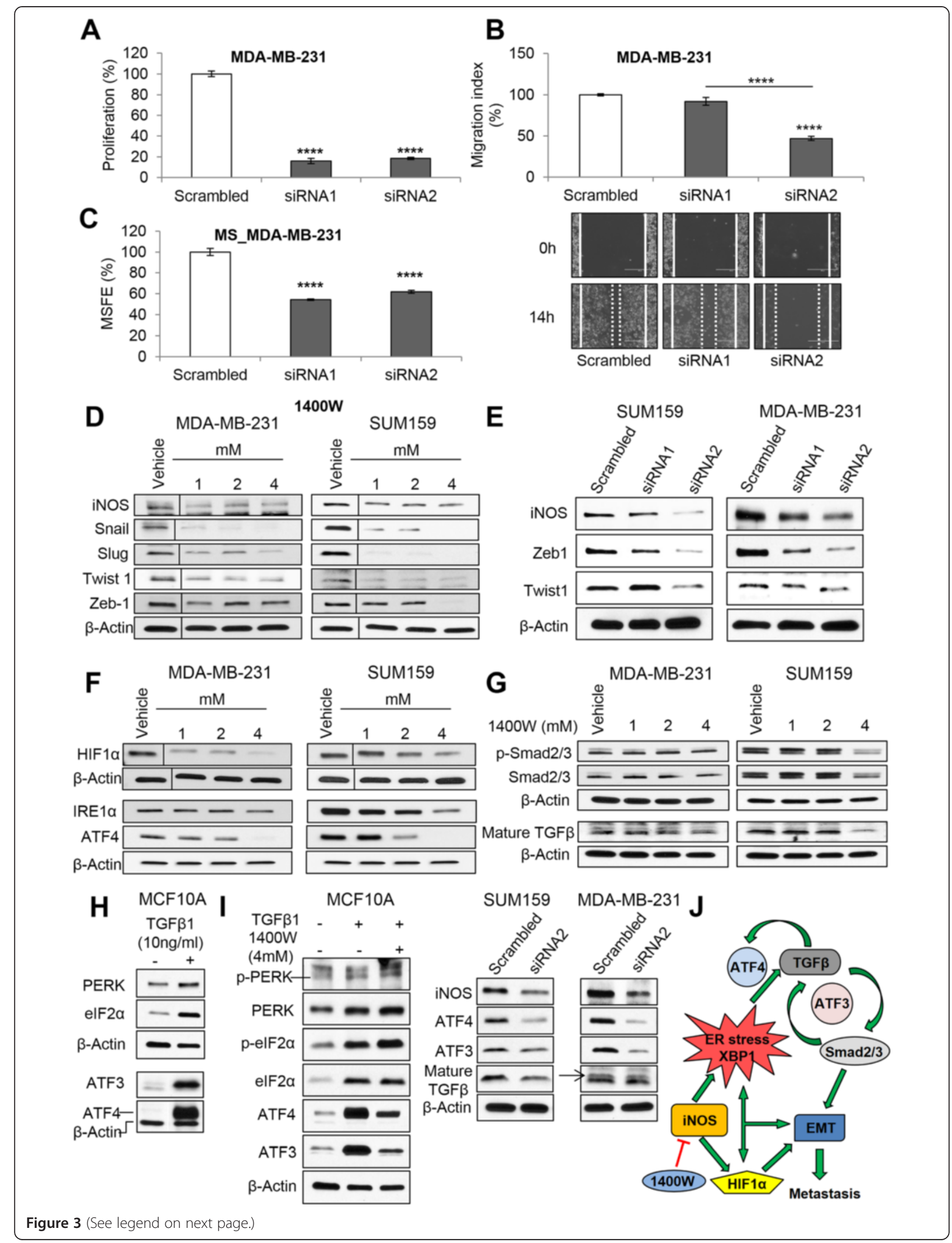




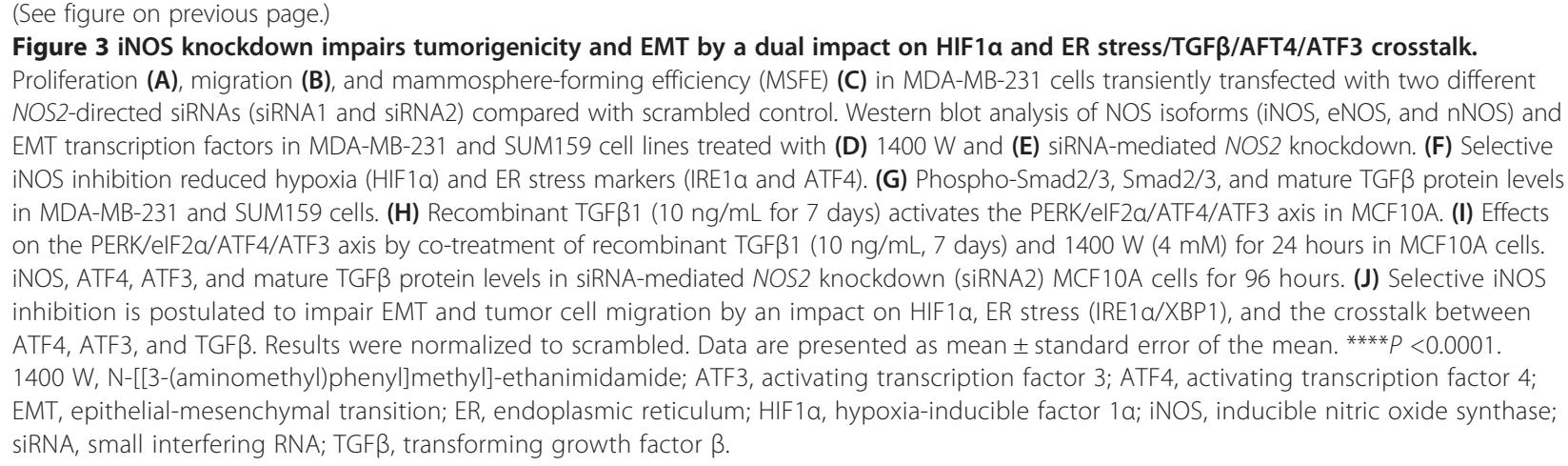

and combination, respectively $(P<0.05)$ (Additional file 6: Figure S6E).

Similarly, docetaxel and L-NMMA (200 mg/kg, daily) were given to MDA-MB-231 xenograft-bearing mice. We found reduced tumor growth in the L-NMMA group compared with vehicle, but there was no change between the docetaxel and combination groups (Figure 5A). These results were further correlated with lower proliferation rate (Ki67) in the L-NMMA and combination groups (Figure 5B and C). Additionally, higher apoptosis levels in docetaxel-treated xenografts were found; these results might offset the high proliferation rate relative to the combination group (Figure 5D). A decrease in MS formation was seen for both L-NMMA and combination compared with vehicle and chemotherapy alone (Figure 5E). LDA showed that the vehicle-treated and docetaxel-treated groups presented $12 / 12$ and $8 / 12$ tumors, respectively, with a significant decrease in L-NMMA-treated (1/12) and combination-treated $(4 / 12)$ xenografts at 5 weeks with $5 \times 10^{4}$ cells. After 6 weeks, a decrease in both the L-NMMA and combination groups (3/12 and 5/12, respectively) compared with the vehicle and docetaxel groups $(6 / 12$ and $8 / 12$, respectively) was observed $(P<0.05)$ (Figure $5 \mathrm{~F}$ ). Our results in the MDA-MB-231 xenograft model do not show additional benefit over chemotherapy in terms of tumor volume; however, it is clear that the benefits of L-NMMA lie in the ability of this inhibitor to reduce self-renewal and tumor initiation capacities of CSCs.

Our investigations demonstrate that L-NMMA plasma levels are cleared rapidly (Additional file 7: Figure S7A), whereas it accumulates in the tumor tissue (Additional file 7: Figure S7B) and inhibits the conversion of L-arginine to L-citrulline and NO by iNOS (Additional file 7: Figure S7C) 24 hours after completion of treatment. This inhibition led to a decrease in total NO production as seen in SUM159 cells (Additional file 7: Figure S7D). Overall, these results demonstrate that in vivo iNOS inhibition with L-NMMA decreased tumor growth, cell proliferation, and tumorinitiating capacity of CSCs, together with a significant reduction in lung metastases.

\section{Efficient dose regimen of L-NMMA and docetaxel with potential clinical application}

Clinically, L-NMMA causes acute BP elevation through inhibition of constitutive eNOS [30]. Here, we propose a regimen with an attenuated duration of L-NMMA, at a dose comparable to that previously described clinically [31], together with the anti-hypertensive amlodipine and docetaxel. Oral L-NMMA significantly increased the mean systolic pressure compared with basal levels in mice, and this elevation was efficiently reversed by amlodipine (Figure 6A). This elevation in BP was transient and disappeared 24 hours after the last injection of L-NMMA (Figure 6B).

The combination of L-NMMA, amlodipine, and docetaxel was able to decrease tumor growth in an MDA-MB231 orthotopic model (Figure $6 \mathrm{C}$ ). This dose regimen also improved survival in comparison with the docetaxeltreated group $(P=0.0001)$ (Figure 6D). Similar results were found in SUM159 xenografts (Figure 6E). We tested the effect of amlodipine on tumor volume in MDA-MB-231 tumor-bearing mice ( $\mathrm{n}=5$ per group). A significant reduction in tumor volume was observed in docetaxel + amlodipine + L-NMMA compared with docetaxel $(P<0.001)$, docetaxel + amlodipine $(P<0.01)$, and docetaxel + L-NMMA $(P<0.05)$ (Figure 6F). Overall, these data show that the dose regimen proposed herein is effective in reducing tumor growth and may result in improved survival.

\section{Discussion}

TNBC is an extremely aggressive and lethal form of cancer lacking effective targeted therapies. Patients with TNBC show higher risk of metastasis and tumor relapse $[1,2]$. We have recently described two novel cancer genes (RPL39 and MLF2) that are important for tumor initiation and metastasis and are regulated by the NO signaling pathway [32]. iNOS predicts for worse survival in patients with basal-like ER-negative breast cancer and has been suggested to increase tumor aggressiveness by modulating CSCs as well as the metastatic propensity of 


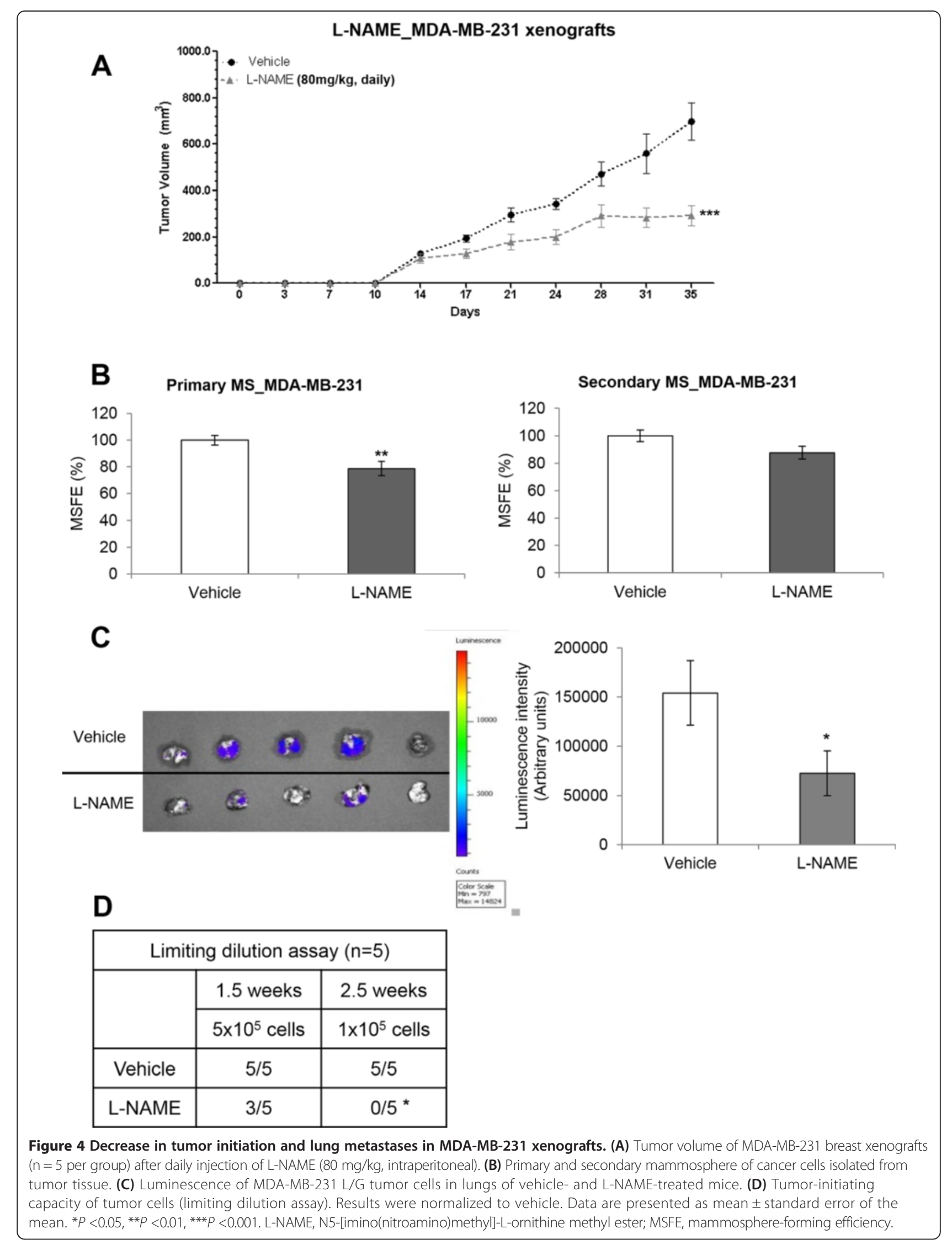




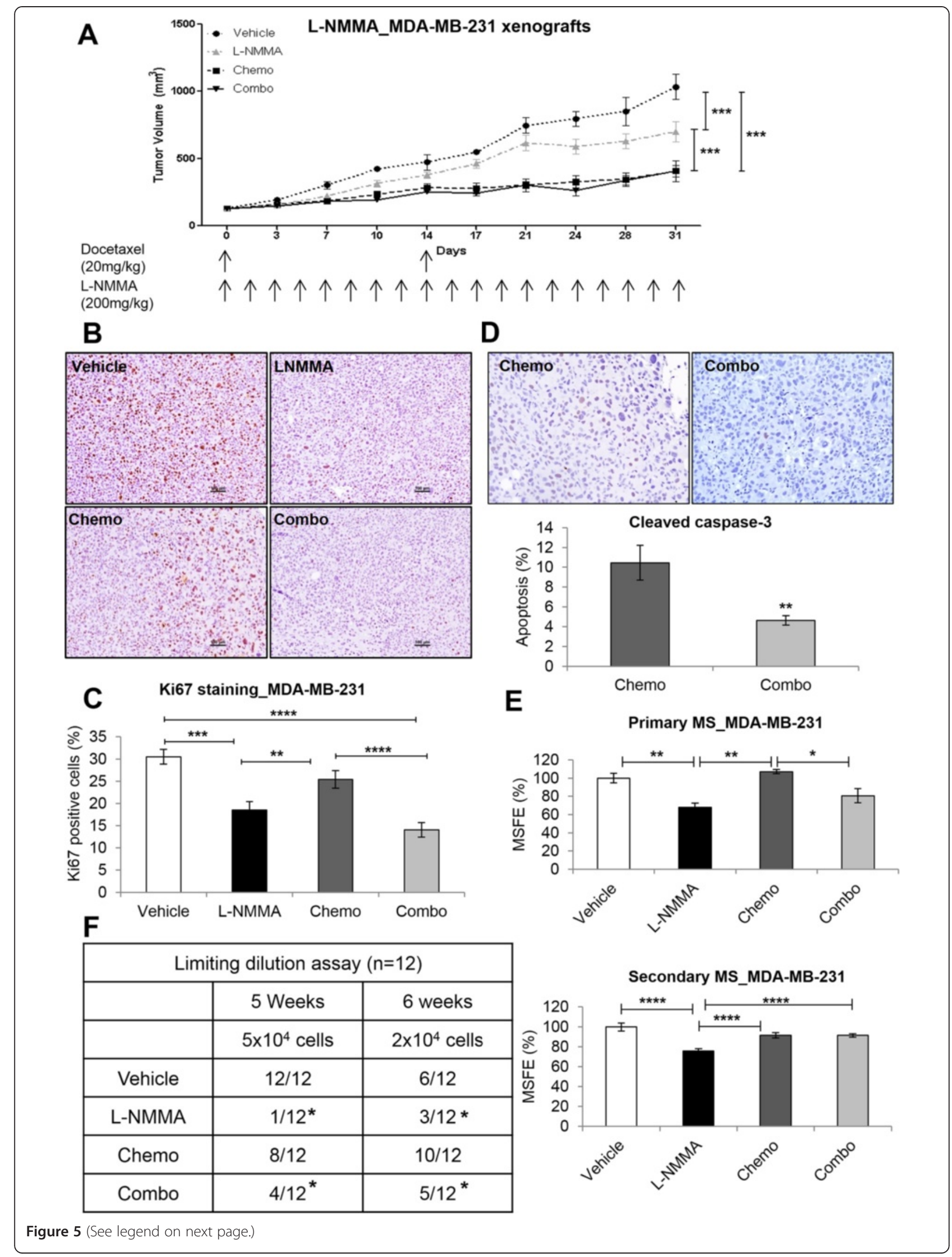


(See figure on previous page.)

Figure $\mathbf{5}$ In vivo effects of L-NMMA in MDA-MB-231 xenografts. (A) Tumor volume of MDA-MB-231 breast xenografts ( $\mathrm{n}=10$ per group) treated with vehicle, L-NMMA, docetaxel, and combination. (B) Illustrative images of Ki67 staining in the vehicle, L-NMMA, docetaxel, and combination groups. Original optical objective: 10x. Counterstain: hematoxylin. (C) Cell proliferation of tumor xenografts with Ki67 immunostaining. (D) Nuclear cleaved caspase-3 staining in the chemo and combo groups. (E) Primary and secondary mammosphere of breast cancer cells isolated from tumor tissue. (F) Tumor-initiating capacity of tumor cells. Results were normalized to vehicle. For proliferation and apoptosis, 1,000 cells were counted from 10 different fields, and the percentage was determined. Data are presented as mean \pm standard error of the mean. ${ }^{*} P<0.05,{ }^{*} P<0.01,{ }^{* * *} P<0.001,{ }^{* * *} P<0.0001$. L-NMMA, $N^{G}$-monomethyl-L-arginine; MSFE, mammosphere-forming efficiency.

cells [7]. This is the first report demonstrating that iNOS inhibition decreases tumorigenicity of TNBC cells by affecting cell proliferation, CSC self-renewal, and migration. Our in vivo experiments demonstrate the efficacy of a small-molecule iNOS inhibitor L-NMMA as a potential novel targeted therapy in patients with TNBC with immediate translation into human clinical trials.

We report that NOS2 is commonly increased in invasive TNBC and is associated with poor survival of patients with invasive breast carcinoma. We provide additional data that high iNOS protein levels by immunohistochemistry in samples of patients with TNBC also correlate with worse outcome, consistent with earlier reports in ER $\alpha$-negative [8] and invasive breast carcinoma [33]. Kaplan-Meier analysis of the Van de Vijver and Curtis databases as well as of the human TNBC patient samples strongly indicate that high iNOS expression is associated with poor overall survival in patients with TNBC. These observations establish that increased iNOS expression may be a marker of poor prognosis in patients with breast cancer [6-9].

iNOS expression has been correlated with increased tumor grade and aggressiveness of breast cancer cells $[7,9]$. Here, we describe the effect of iNOS on CSC selfrenewal, tumor initiation, and the migrating capacity of TNBC cells. The anti-tumor activity of iNOS inhibitors has been previously reported in oral [34], glioblastoma [13], and breast cancer [35-38] and is consistent with our findings. Increased iNOS expression has been described to contribute to resistance to conventional treatment by promoting tumor initiation in glioblastoma cells $[13,38]$. Additionally, iNOS may influence CSC self-renewal by modulating $C D 44$ and $c-M y c$ in ER $\alpha$-negative breast cancer [7]. We demonstrate for the first time that iNOS inhibition decreased CSC self-renewal and tumor initiation in TNBC.

NO may either promote or inhibit metastatic events depending on endogenous levels [5]. The role of NOS inhibitors on metastasis has been previously studied, but the underlying mechanisms remain unclear. An early study demonstrated that the pan-NOS inhibitor L-NAME may decrease tumor growth and lung metastasis in a murine breast cancer model (EMT-6 cells) [39]. Similarly, L-NAME inhibited the invasive and migrating potential of two metastatic mammary cell lines (C3L5 and C10) [40].
In a study with the metastatic human adenocarcinoma HRT-18 cells, the invasiveness was substantially decreased by daily treatment with $500 \mu \mathrm{M}$ of the selective iNOS inhibitor $1400 \mathrm{~W}$ [41]. More recently, $1400 \mathrm{~W}$ was shown to markedly inhibit spontaneous lung metastasis in a mouse model of adenoid cystic carcinoma of the oral cavity [34]. Our present results demonstrate that iNOS inhibition decreases cell migration and lung metastases in TNBC. It has been suggested that NO and iNOS may lead to early metastasis by inducing $I L-8$ [7] and the CXC chemokine receptor 4 [42]. CSCs display mesenchymal features [2], resulting in increased cell migration and metastasis. iNOS inhibition decreased CSC self-renewal and tumor initiation, thus indicating that inhibitors against this pathway could reverse the transition of tumor cells to a more mesenchymal-like phenotype. Consistent with the effect on cell migration, selective iNOS inhibition and NOS2 knockdown decreased transcription factors driving EMT in all of the TNBC cell lines tested.

EMT may be promoted by different signal transduction pathways like TGF $\beta$, Wnt/ $\beta$-catenin, Notch, and Hedgehog and multiple growth factors. EMT transcription factors (Snail, Slug, Twist1, or Zeb1) are activated by diverse intermediate effectors like c-Myc, Ets, HIF1 $\alpha$, or NFKB [43]. Additionally, ER stress has been linked to EMT in thyroid, alveolar epithelial, and human renal proximal tubule cells through activation of PERK, XBP1, or Grp78 [27,44-46]. Interestingly, among these disparate signaling networks, iNOS is the common denominator between HIF1 $\alpha$ and ER stress [25-27]. Inhibition of endogenous iNOS-derived NO production was able to reduce HIF1 $\alpha$ stabilization and protein levels in colon carcinoma cells [47]. Transcription factors Twist1, Snail, Slug, and Zeb1, among others, are directly or indirectly influenced by HIF1 $\alpha$ [26]. Additionally, hypoxia induces ER stress and unfolded protein response and was recently linked to migration and sphere formation in breast cancer cells by activation of the PERK/ATF4/LAMP3 arm under hypoxic conditions [48]. Our results suggest that iNOS inhibition correlates with an impairment of TGF $\beta$ signaling via the ER stress ATF4/ATF3 axis. It is known that TGF $\beta$ stimulates ATF4 protein levels to suppress differentiation in calvarial osteoblasts [29]. Certain conditions such as ER stress through the PERK/eIF2 $\alpha$ axis may activate ATF4, which in turn induces ATF3 
A

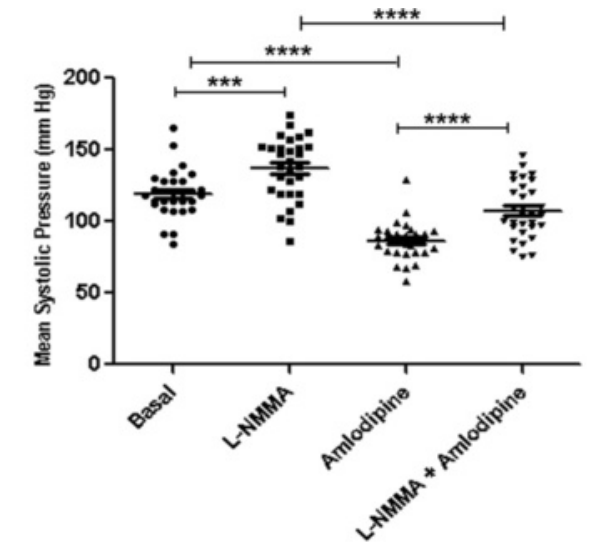

C

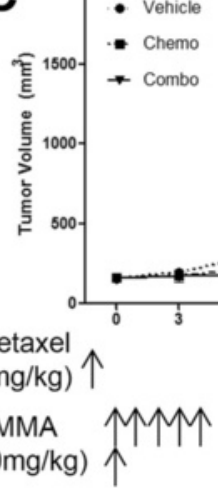

Amlodipine
$(10 \mathrm{mg} / \mathrm{kg})$

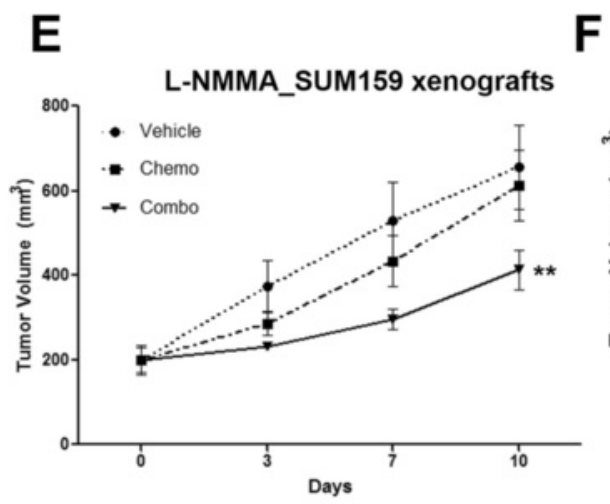

Docetaxel $\uparrow$

$(20 \mathrm{mg} / \mathrm{kg})$ 个

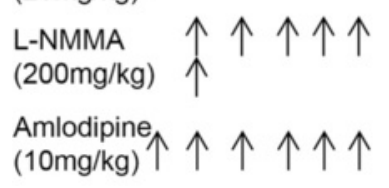
$\uparrow$

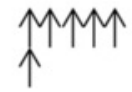

$\uparrow \uparrow \uparrow \uparrow \uparrow$
B

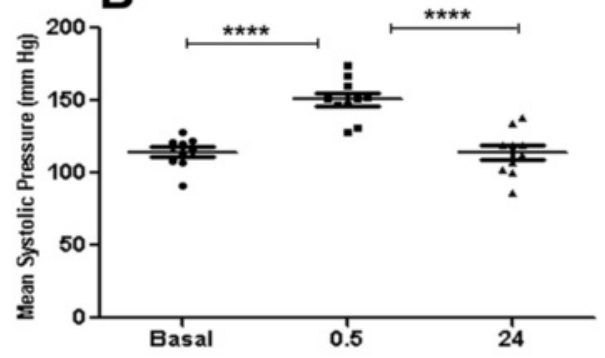

Hours after last injection

D

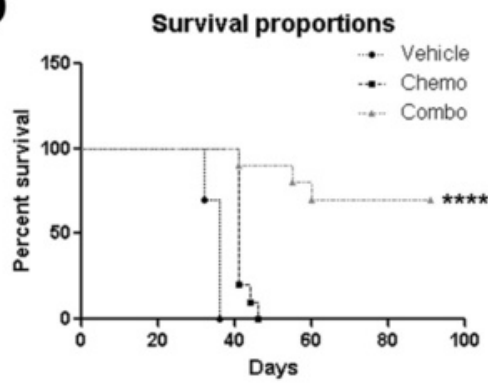

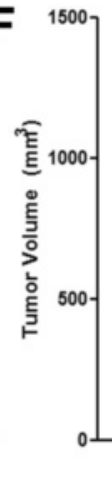

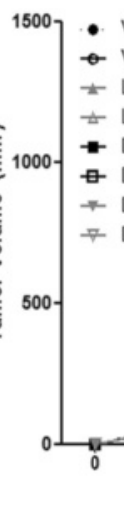

- Veh

Veh

+ Amlo

L-NMMA

- L-NMMA+Amlo

- Docetaxel

- Docetaxel+Amlo Ins Ins Ins T T.

- Docetaxel+L-NMMA+Amlo $I^{*} I^{* *} I^{* * *}$

MDA-MB-231 xenografts

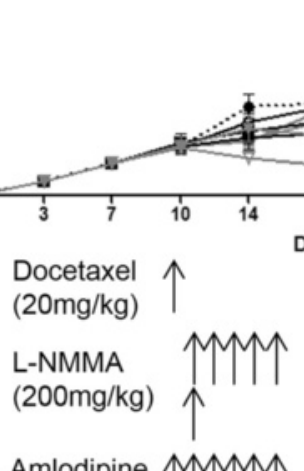

Amlodipine

(10 mg/kg)

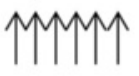

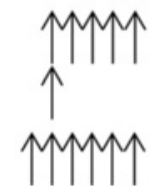

Figure 6 Clinically relevant dose regimen of L-NMMA in orthotopic mouse models of triple-negative breast cancer. (A) Mean systolic pressure of mice $(n=5)$ giving one cycle of the dose rate proposed in this study. (B) Mean systolic pressure of mice 30 minutes and 24 hours after the last injection of one cycle treatment $(n=5)$. (C) Tumor volume of MDA-MB-231 xenografts $(n=10$ per group) treated with vehicle, docetaxel, and combination (docetaxel + amlodipine + L-NMMA). (D) Kaplan-Meier survival curve of vehicle-, chemotherapy-, and combo-treated MDA-MB-231 xenograft-bearing mice. (E) Tumor volume of SUM159 xenografts ( $n=10$ per group) treated with vehicle, docetaxel, and combination. (F) Effects of amlodipine on tumor volume in MDA-MB-231 xenografts ( $n=5$ per group). Data are presented as mean \pm standard error of the mean. ${ }^{*} P<0.05,{ }^{*} P<0.01,{ }^{* *} P<0.001,{ }^{* * *} P<0.0001$. L-NMMA, $N^{G}$-monomethyl-L-arginine; ns, not significant. 
transcription [49], whereas ATF3 itself is an activating transcription factor that enhances TGF $\beta$, MS formation, and EMT in cooperation with Twist1 [28].

To determine a safe and effective regimen with clinical applicability was the main challenge of these preclinical studies. L-NMMA is a pan-NOS inhibitor that has been extensively studied in several clinical trials of circulatory shock [30]. In the cardiogenic shock trial, L-NMMA was safe and had few adverse events other than transient reversible hypertension [31]. In normotensive patients, L-NMMA was administered to patients with metastatic renal cell carcinoma prior to infusion of IL-2 [31]. Doses of 3 and $6 \mathrm{mg} / \mathrm{kg}$ did not induce clinically apparent side effects, and BP remained unchanged. At a dose level of $12 \mathrm{mg} / \mathrm{kg}$, patients experienced an increase in systolic BP up to $25 \mathrm{~mm} \mathrm{Hg}$, without any clinical symptoms, which normalized rapidly on stopping the L-NMMA infusion. The dose rate in the present study was chosen, with modifications, on the basis of a previous clinical trial in patients with septic shock [31]. Our results demonstrate that tumor growth can be restrained by an attenuated regimen of 5 days of L-NMMA after chemotherapy, given together with amlodipine. López et al. [50] carried out a randomized, placebo-controlled, double-blind study of L-NMMA in patients with septic shock up to a maximum of 14 days. The regimen followed consisted of an initial dose of $2.5 \mathrm{mg} / \mathrm{kg}$ per hour and then was adjusted at different rates $(0.5,1,2.5,5,7.5,10,15$, and $20 \mathrm{mg} / \mathrm{kg}$ per hour). The current proposed dose regimen to be clinically tested as a novel anti-cancer therapeutic is at much lower total doses, which have been described [50].

\section{Conclusions}

Our study provides new knowledge about the correlation between enhanced endogenous iNOS expression and poor survival in patients with TNBC. We show that the targeted therapy with iNOS inhibitors is able to inhibit not only tumor cell proliferation but also CSC selfrenewal and migration, reducing tumor growth, tumor initiation, and the number of lung metastases. We suggest that inhibition of metastatic events may be due to a reduction of EMT transcription factors by inhibition of HIF1 $\alpha$, ER stress (IRE1 $\alpha /$ splicedXBP1), and the TGF $\beta$ / ATF4/ATF3 axis. Finally, we propose a targeted therapeutic regimen, which decreases tumor growth and enhances survival rate in vivo; clinical trials targeting this pathway in patients with TNBC are being planned.

\section{Additional files}

Additional file 1: L-NAME, $1400 \mathrm{~W}$, and L-NMMA (micromolar range) on proliferation, migration, and mammosphere formation of TNBC cell lines. Proliferation (A) and primary (B) and secondary (C) mammospheres of MDA-MB-231 and SUM159 cell lines treated with L-NAME. Impact of $1400 \mathrm{~W}$ (D) and L-NMMA (E) at micromolar concentrations on the migration index in MDA-MB-231 and SUM159 cells. Results were normalized to vehicle. Data are presented as mean \pm standard error of the mean. ${ }^{*} P<0.05,{ }^{* *} P<0.01$, ${ }^{* * *} P<0.001,{ }^{* * * *} P<0.0001 .1400 \mathrm{~W}, \mathrm{~N}-[[3$-(aminomethyl) phenyl]methyl]-ethanimidamide; L-NMMA, N ${ }^{G}$-monomethyl-L-arginine; TNBC, triple-negative breast cancer.

Additional file 2: Representative images of mammospheres in MDA-MB-231 cells treated with iNOS inhibitors. Illustrative images of primary (A) and secondary (B) mammospheres after treatment with 1400 W, L-NMMA (vehicle, 1, 2, 4 mM), and L-NAME (vehicle, 1, 2, 5 mM) for 96 hours. 1400 W, N-[[3-(aminomethyl)phenyl]methyl]-ethanimidamide; L-NAME, N5-[imino(nitroamino)methyl]-L-ornithine methyl ester; L-NMMA, $N^{G}$-monomethyl-L-arginine; iNOS, inducible nitric oxide synthase.

Additional file 3: Representative images of mammospheres in SUM159 cells treated with iNOS inhibitors. Illustrative images of primary (A) and secondary (B) mammospheres after treatment with $1400 \mathrm{~W}$, L-NMMA (vehicle, 1, 2, 4 mM), and L-NAME (vehicle, 1, 2, $5 \mathrm{mM}$ ) for 96 hours. 1400 W, N-[[3-(aminomethyl)phenyl]methyl]-ethanimidamide; L-NAME, N5-[imino(nitroamino)methyl]-L-ornithine methyl ester; L-NMMA, $N^{G}$-monomethyl-L-arginine; iNOS, inducible nitric oxide synthase.

Additional file 4: Migration and Western blot of NOS isoforms, EMT transcription factors, and hypoxia in TNBC cell lines treated with iNOS inhibitors. (A) Tumor cell migration after treatment with L-NAME in MDA-MB-231 and SUM159 cell lines. (B, C) Western blot analysis of NOS isoforms (iNOS, eNOS, and nNOS) in MDA-MB-231 and SUM159 cells treated with $1400 \mathrm{~W}$ and L-NMMA. (D, E) EMT markers protein levels in MDA-MB-231 and SUM159 cells after treatment with micromolar concentrations of 1400 W or L-NMMA. (F) Western blot analysis of NOS isoforms and the EMT transcription factors in MDA-MB-231 and SUM159 cell lines treated with L-NAME. (G) Quantification of HIF1a protein levels relative to $\beta$-actin in MDA-MB-231 and SUM159 cells treated with $1400 \mathrm{~W}$. Results were normalized to vehicle. Data are presented as mean \pm standard error of the mean. ${ }^{*} P<0.05,{ }^{* *} P<0.01$. 1400 W, N-[[3-(aminomethyl)phenyl]methyl]ethanimidamide; EMT, epithelial-mesenchymal transition; eNOS, endothelial nitric oxide synthase; HIF1a, hypoxia-inducible factor 1a; iNOS, inducible nitric oxide synthase; L-NAME, N5-[imino(nitroamino)methyl]-L-ornithine methyl ester; L-NMMA, N ${ }^{G}$-monomethyl-L-arginine; iNOS, inducible nitric oxide synthase; nNOS, neuronal nitric oxide synthase; TNBC, triple-negative breast cancer.

Additional file 5: NOS2 knockdown decreases cell proliferation, migration, mammosphere formation, spliced XBP1, and Smad2/3 signaling. Crosstalk between ER stress and TGF $\beta$ is shown. Proliferation (A), migration (B), and mammospheres (C) of SUM159 cells transiently transfected with two different NOS2-directed siRNAs (siRNA1 and siRNA2) compared with scrambled control. (D) Protein-protein interaction analysis (STRING 9.1) deciphered a link between NOS2, TGF 1 , and ATF4/ATF3 axis. (E) Unspliced XBP1 (UXBP1), spliced XBP1 (sXBP1), and $\beta$-actin RT-PCR CDNA amplicons from MDA-MB-231 cells treated with $1400 \mathrm{~W}$ for 96 hours. (F) The iNOS inhibitor $1400 \mathrm{~W}$ is able to reduce the Smad2/3 signaling in MDA-MB-231 cells under treatment with recombinant TGF $\beta 1(10 \mathrm{ng} / \mathrm{mL})$ for 72 hours. (G) Tunicamycin $(5 \mu \mathrm{M})$ confirmed the crosstalk between ER stress and TGF $\beta$ through ATF4/ATF3 transcription factors. Results were normalized to scrambled control. Data are presented as mean \pm standard error of the mean. ${ }^{*} P<0.05,{ }^{*} P<0.01$, ${ }^{* * *} P<0.001,{ }^{* * *} P<0.0001 .1400 \mathrm{~W}$, $\mathrm{N}$-[[3-(aminomethyl)phenyl]methyl]-ethanimidamide; ATF3, activating transcription factor 3; ATF4, activating transcription factor 4; ER, endoplasmic reticulum; iNOS, inducible nitric oxide synthase; NOS2, nitric oxide synthase 2; RT-PCR, reverse transcription-polymerase chain reaction; shRNA, small hairpin RNA; siRNA, small interfering RNA; TGF 3 , transforming growth factor $\beta$.

Additional file 6: In vivo effects of L-NMMA in SUM159 xenografts. (A) Tumor volume of SUM159 breast xenografts ( $n=10$ per group) treated with vehicle, L-NMMA, chemotherapy, and combination. (B) Illustrative images of Ki67 staining in vehicle, L-NMMA, chemotherapy (docetaxel), and combination groups. Original optical objective: 10×. Counterstain: hematoxylin. (C) Cell proliferation of tumor xenografts is depicted as Ki67-positive cells. Cells $(1,000)$ were counted from 10 different fields, and the percentage was determined. (D) Primary and secondary mammospheres of breast 
cancer cells isolated from tumor tissue. (E) Tumor-initiating capacity of tumor cells assayed by the limiting dilution method. Results were normalized to vehicle. Data are presented as mean \pm standard error of the mean. ${ }^{*} P<0.05,{ }^{* *} P<0.01,{ }^{* * *} P<0.001,{ }^{* * * *} P<0.0001$. L-NMMA, $\mathrm{N}^{G}$-monomethyl-L-arginine.

Additional file 7: L-NMMA levels in plasma and tumor tissue. (A, B) Ratiometric quantification of methylarginine in plasma and tumor tissue (MDA-MB-231 and SUM159 xenografts) by liquid chromatography-tandem mass spectrometry (LC-MS/MS). (C) iNOS catalyzes the reaction of $\mathrm{L}$-arginine to $\mathrm{L}$-citrulline + nitric oxide (NO). Ratiometric quantification of citrulline in SUM159 xenograft tissue by LC-MS/MS. (D) Total NO production in SUM159 cells treated with L-NMMA and 1400 W (4 mM) for 0.5, 2, 6, and 24 hours. Results were normalized to vehicle. Data are presented as mean \pm standard error of the mean. ${ }^{*} P<0.05$, ${ }^{* * P}<0.01,{ }^{* * * P}<<0.001,{ }^{* * * *} P<0.0001 .1400 \mathrm{~W}, \mathrm{~N}$-[[3-(aminomethyl)phenyl] methyl]-ethanimidamide; L-NMMA, $N^{G}$-monomethyl-L-arginine; iNOS, inducible nitric oxide synthase.

\section{Abbreviations}

1400 W: N-[[3-(aminomethyl)phenyl]methyl]-ethanimidamide; ANOVA: analysis of variance; ATF3: activating transcription factor 3; ATF4: activating transcription factor 4; BP: blood pressure; CSC: cancer stem cell; DMEM: Dulbecco's modified Eagle's medium; EMT: epithelial-mesenchymal transition; eNOS: endothelial nitric oxide synthase; ER: endoplasmic reticulum; ERa: estrogen receptor alpha; HIF1a: hypoxia-inducible factor 1a; IL-8: interleukin-8; iNOS: inducible nitric oxide synthase; i.p.: intraperitoneal; LDA: limiting dilution assay; L-NAME: N5-[imino(nitroamino)methyl]-L-ornithine methyl ester; L-NMMA: $N^{G}$-monomethyl-L-arginine; MS: mammosphere;

MSFE: mammosphere-forming efficiency; nNOS: neuronal nitric oxide synthase; NO: nitric oxide; NOS: nitric oxide synthase; PCR: polymerase chain reaction; SCID: severe combined immunodeficiency; shRNA: small hairpin RNA; siRNA: small interfering RNA; TCGA: The Cancer Genome Atlas; TGF $\beta$ : transforming growth factor $\beta$; TNBC: triple-negative breast cancer.

\section{Competing interests}

SSG is a partner in Arginox Pharmaceuticals. The other authors declare that they have no competing interests.

\section{Authors' contributions}

SG-P performed and designed the majority of the experiments, analyzed the data, and drafted the manuscript. YL assisted in the generation of the metastatic model of MDA-MB-231 L/G xenografts and the acquisition of bioluminescence data. MLG assisted with the in vitro data acquisition and Western blot experiments with L-NMMA. EB and DSC assisted in the treatments and measurement of tumor volume in the animal experiments. WQ performed the immunohistochemistry in TMA of xenograft and patient tissues. TP and AAR managed patients and collected the clinical outcome and patient samples. JC assisted with evaluating and scoring the levels of iNOS in TMAs from xenograft and patient tissues. HLW performed the biostatistics and computational analysis to correlate the iNOS levels in the patients' TMA and the clinical outcome. HZ performed the analysis of NOS2 mRNA expression in human TNBC with the Oncomine Cancer Microarray database of TCGA. MDL and BD assisted in the statistical analysis, interpretation of the clinical data, and review of the manuscript. SSG gave financial support, performed the metabolite profiling by liquid chromatography-tandem mass spectrometry, provided L-NMMA, and assisted in the interpretation of the animal data and revision of the manuscript. JCC conceived the project, supervised the study, provided financial support, and contributed to the writing and critical reviewing of the final manuscript. All authors have made substantial contributions to the design of experiments, data analysis, and drafting of the manuscript. All authors have reviewed and approved the final version of this manuscript and agree to be accountable for all aspects of the work presented herein.

\section{Acknowledgments}

This work was supported by National Institutes of Health/National Cancer Institute grant R01 CA138197 (JCC), U54 CA149196 (JCC), Golfers Against Cancer (JCC), Breast Cancer Research Foundation (JCC), Causes for a Cure (JCC), Team Tiara (JCC), Emily W. Herrman Cancer Research Laboratory (JCC), Department of Defense Innovator Expansion Award BC104158 (JCC), Komen for Cure KG 081694 (JCC), National Institutes of Health Merit Award grant R37 HL87062 (SSG), and Fundacion Alfonso Martin Escudero (SG-P). We thank Dr. Madhumita Ghosh for critical reading and editing of the manuscript.

\section{Author details}

'Methodist Cancer Center, Houston Methodist Hospital, 6445 Main Street, P21-34, Houston, TX 77030, USA. ${ }^{2}$ Medical and Health Sciences College, Monterrey Institute of Technology, Eugenio Garza Sada 2501, Monterrey, NL 64849, Mexico. ${ }^{3}$ Department of Nanomedicine, Houston Methodist Research Institute, 6670 Bertner Avenue, Houston, TX 77030, USA. ${ }^{4}$ Department of Chemistry and Biochemistry, Arizona State University, 551 E University Dr., Tempe, AZ 85287, USA. ${ }^{5}$ Biostatistics Shared Resource Facility, Markey Cancer Center, University of Kentucky, 800 Rose Street, Lexington, KY 40536-0093, USA. ${ }^{6}$ Department of Systems Medicine and Bioengineering, Houston Methodist Research Institute, 6670 Bertner Avenue, Houston, TX 77030, USA. ${ }^{7}$ Weill Cornell Medical College, 1300 York Avenue, New York, NY 10065, USA.

Received: 21 August 2014 Accepted: 29 January 2015 Published online: 22 February 2015

\section{References}

1. Chang JC, Wooten EC, Tsimelzon A, Hilsenbeck SG, Gutierrez MC, Tham YL, et al. Patterns of resistance and incomplete response to docetaxel by gene expression profiling in breast cancer patients. J Clin Oncol. 2005;23:1169-77.

2. Creighton CJ, Li X, Landis M, Dixon JM, Neumeister VM, Sjolund A, et al. Residual breast cancers after conventional therapy display mesenchymal as well as tumor-initiating features. Proc Natl Acad Sci U S A. 2009;106:13820-5.

3. Dave B, Mittal V, Tan NM, Chang JC. Epithelial-mesenchymal transition, cancer stem cells and treatment resistance. Breast Cancer Res. 2012;14:202.

4. Schott AF, Landis MD, Dontu G, Griffith KA, Layman RM, Krop I, et al. Preclinical and clinical studies of gamma secretase inhibitors with docetaxel on human breast tumors. Clin Cancer Res. 2013;19:1512-24.

5. Burke AJ, Sullivan FJ, Giles FJ, Glynn SA. The yin and yang of nitric oxide in cancer progression. Carcinogenesis. 2013;34:503-12.

6. Bulut AS, Erden E, Sak SD, Doruk H, Kursun N, Dincol D. Significance of inducible nitric oxide synthase expression in benign and malignant breast epithelium: an immunohistochemical study of 151 cases. Virchows Arch. 2005;447:24-30.

7. Glynn SA, Boersma BJ, Dorsey TH, Yi M, Yfantis HG, Ridnour LA, et al. Increased NOS2 predicts poor survival in estrogen receptor-negative breast cancer patients. J Clin Invest. 2010;120:3843-54.

8. Loibl S, Buck A, Strank C, von Minckwitz G, Roller M, Sinn HP, et al. The role of early expression of inducible nitric oxide synthase in human breast cancer. Eur J Cancer. 2005;41:265-71.

9. Thomsen LL, Miles DW, Happerfield L, Bobrow LG, Knowles RG, Moncada S. Nitric oxide synthase activity in human breast cancer. Br J Cancer. 1995;72:41-4.

10. Okayama H, Saito M, Oue N, Weiss JM, Stauffer J, Takenoshita S, et al. NOS2 enhances KRAS-induced lung carcinogenesis, inflammation and microRNA-21 expression. Int J Cancer. 2013;132:9-18.

11. Ambs S, Merriam WG, Bennett WP, Felley-Bosco E, Ogunfusika MO, Oser SM, et al. Frequent nitric oxide synthase-2 expression in human colon adenomas: implication for tumor angiogenesis and colon cancer progression. Cancer Res. 1998:58:334-41.

12. Massi D, Franchi A, Sardi I, Magnelli L, Paglierani M, Borgognoni L, et al. Inducible nitric oxide synthase expression in benign and malignant cutaneous melanocytic lesions. J Pathol. 2001;194:194-200.

13. Eyler $C E$, Wu Q, Yan K, MacSwords JM, Chandler-Militello D, Misuraca KL, et al. Glioma stem cell proliferation and tumor growth are promoted by nitric oxide synthase-2. Cell. 2011;146:53-66.

14. Switzer $\mathrm{CH}$, Cheng RY, Ridnour LA, Glynn SA, Ambs S, Wink DA. Ets-1 is a transcriptional mediator of oncogenic nitric oxide signaling in estrogen receptor-negative breast cancer. Breast Cancer Res. 2012;14:R125.

15. Alexander JH, Reynolds HR, Stebbins AL, Dzavik V, Harrington RA, Van de Werf $F$, et al. Effect of tilarginine acetate in patients with acute myocardial infarction and cardiogenic shock: the TRIUMPH randomized controlled trial. JAMA. 2007;297:1657-66.

16. Rhodes DR, Kalyana-Sundaram S, Mahavisno V, Varambally R, Yu J, Briggs BB, et al. Oncomine 3.0: genes, pathways, and networks in a collection of 18,000 cancer gene expression profiles. Neoplasia. 2007;9:166-80. 
17. van de Vijver MJ, He YD, van't Veer LJ, Dai H, Hart AA, Voskuil DW, et al. A gene-expression signature as a predictor of survival in breast cancer. N Engl J Med. 2002;347:1999-2009.

18. Curtis C, Shah SP, Chin SF, Turashvili G, Rueda OM, Dunning MJ, et al. The genomic and transcriptomic architecture of 2,000 breast tumours reveals novel subgroups. Nature. 2012;486:346-52.

19. Chen Q, Park HC, Goligorsky MS, Chander P, Fischer SM, Gross SS. Untargeted plasma metabolite profiling reveals the broad systemic consequences of xanthine oxidoreductase inactivation in mice. PLoS One. 2012;7:e37149.

20. Babykutty S, Suboj P, Srinivas P, Nair AS, Chandramohan K, Gopala S. Insidious role of nitric oxide in migration/invasion of colon cancer cells by upregulating MMP-2/9 via activation of cGMP-PKG-ERK signaling pathways. Clin Exp Metastasis. 2012;29:471-92.

21. Pang Y, Gara SK, Achyut BR, Li Z, Yan HH, Day CP, et al. TGF- $\beta$ signaling in myeloid cells is required for tumor metastasis. Cancer Discov. 2013;3:936-51.

22. Chen J, Li Y, Yu TS, McKay RM, Burns DK, Kernie SG, et al. A restricted cell population propagates glioblastoma growth after chemotherapy. Nature. 2012;488:522-6.

23. Driessens G, Beck B, Caauwe A, Simons BD, Blanpain C. Defining the mode of tumour growth by clonal analysis. Nature. 2012;488:527-30.

24. Thiery JP, Acloque H, Huang RY, Nieto MA. Epithelial-mesenchymal transitions in development and disease. Cell. 2009;139:871-90.

25. Matrone C, Pignataro G, Molinaro P, Irace C, Scorziello A, Di Renzo GF, et al. HIF-1alpha reveals a binding activity to the promoter of iNOS gene after permanent middle cerebral artery occlusion. J Neurochem. 2004;90:368-78.

26. Yang MH, Wu KJ. TWIST activation by hypoxia inducible factor-1 (HIF-1): implications in metastasis and development. Cell Cycle. 2008;7:2090-6.

27. Zhong Q, Zhou B, Ann DK, Minoo P, Liu Y, Banfalvi A, et al. Role of endoplasmic reticulum stress in epithelial-mesenchymal transition of alveolar epithelial cells: effects of misfolded surfactant protein. Am J Respir Cell Mol Biol. 2011:45:498-509.

28. Yin X, Wolford CC, Chang YS, McConoughey SJ, Ramsey SA, Aderem A, et al. ATF3, an adaptive-response gene, enhances TGF $\{$ beta\} signaling and cancer-initiating cell features in breast cancer cells. J Cell Sci. 2010;123:3558-65

29. Lian N, Lin T, Liu W, Wang W, Li L, Sun S, et al. Transforming growth factor $\beta$ suppresses osteoblast differentiation via the vimentin activating transcription factor 4 (ATF4) axis. J Biol Chem. 2012;287:35975-84.

30. Kilbourn RG, Szabó C, Traber DL. Beneficial versus detrimental effects of nitric oxide synthase inhibitors in circulatory shock: lessons learned from experimental and clinical studies. Shock. 1997;7:235-46.

31. Kilbourn RG, Fonseca GA, Trissel LA, Griffith OW. Strategies to reduce side effects of interleukin-2: evaluation of the antihypotensive agent NG-monomethyl-Larginine. Cancer J Sci Am. 2000;6:21-30.

32. Dave B, Granados-Principal S, Zhu R, Benz S, Rabizadeh S, Soon-Shiong P, et al. Targeting RPL39 and MLF2 reduces tumor initiation and metastasis in breast cancer by inhibiting nitric oxide synthase signaling. Proc Natl Acad Sci U S A. 2014;111:8838-43.

33. Vakkala M, Kahlos K, Lakari E, Pääkkö P, Kinnula V, Soini Y. Inducible nitric oxide synthase expression, apoptosis, and angiogenesis in in situ and invasive breast carcinomas. Clin Cancer Res. 2000;6:2408-16.

34. Takaoka K, Hidaka S, Hashitani S, Segawa E, Yamamura M, Tanaka N, et al. Effect of a nitric oxide synthase inhibitor and a CXC chemokine receptor-4 antagonist on tumor growth and metastasis in a xenotransplanted mouse model of adenoid cystic carcinoma of the oral floor. Int J Oncol. 2013:43:737-45.

35. Chinje EC, Williams KJ, Telfer BA, Wood PJ, van der Kogel AJ, Stratford IJ. 17beta-Oestradiol treatment modulates nitric oxide synthase activity in MDA231 tumour with implications on growth and radiation response. Br J Cancer. 2002;86:136-42.

36. Radisavljevic Z. Inactivated tumor suppressor $\mathrm{Rb}$ by nitric oxide promotes mitosis in human breast cancer cells. J Cell Biochem. 2004;92:1-5.

37. Sen S, Kawahara B, Chaudhuri G. Mitochondrial-associated nitric oxide synthase activity inhibits cytochrome c oxidase: implications for breast cancer. Free Radic Biol Med. 2013;57:210-20.

38. Kim RK, Suh Y, Cui YH, Hwang E, Lim EJ, Yoo KC, et al. Fractionated radiation-induced nitric oxide promotes expansion of glioma stem-like cells. Cancer Sci. 2013;104:1172-7.

39. Edwards P, Cendan JC, Topping DB, Moldawer LL, MacKay S, Copeland EMIII, et al. Tumor cell nitric oxide inhibits cell growth in vitro, but stimulates tumorigenesis and experimental lung metastasis in vivo. J Surg Res. 1996;63:49-52.

40. Jadeski LC, Hum KO, Chakraborty C, Lala PK. Nitric oxide promotes murine mammary tumour growth and metastasis by stimulating tumour cell migration, invasiveness and angiogenesis. Int J Cancer. 2000;86:30-9.

41. Siegert A, Rosenberg C, Schmitt WD, Denkert C, Hauptmann S. Nitric oxide of human colorectal adenocarcinoma cell lines promotes tumour cell invasion. Br J Cancer. 2002;86:1310-5.

42. Yasuoka H, Tsujimoto M, Yoshidome K, Nakahara M, Kodama R, Sanke T, et al. Cytoplasmic CXCR4 expression in breast cancer: induction by nitric oxide and correlation with lymph node metastasis and poor prognosis. BMC Cancer. 2008;8:340.

43. Voutsadakis IA. The ubiquitin-proteasome system and signal transduction pathways regulating Epithelial Mesenchymal transition of cancer. J Biomed Sci. 2012;19:67.

44. Carlisle RE, Heffernan A, Brimble E, Liu L, Jerome D, Collins CA, et al. TDAG51 mediates epithelial-to-mesenchymal transition in human proximal tubular epithelium. Am J Physiol Renal Physiol. 2012;303:F467-81.

45. Tanjore H, Cheng DS, Degryse AL, Zoz DF, Abdolrasulnia R, Lawson WE, et al. Alveolar epithelial cells undergo epithelial-to-mesenchymal transition in response to endoplasmic reticulum stress. J Biol Chem. 2011;286:30972-80.

46. Ulianich L, Garbi C, Treglia AS, Punzi D, Miele C, Raciti GA, et al. ER stress is associated with dedifferentiation and an epithelial-to-mesenchymal transition-like phenotype in PC Cl3 thyroid cells. J Cell Sci. 2008;121:477-86.

47. Chowdhury R, Godoy LC, Thiantanawat A, Trudel L, Deen WM, Wogan GN Nitric oxide produced endogenously is responsible for hypoxia-induced HIF-1a stabilization in colon carcinoma cells. Chem Res Toxicol. 2012;25:2194-202

48. Nagelkerke A, Bussink J, Mujcic H, Wouters BG, Lehmann S, Sweep FC, et al Hypoxia stimulates migration of breast cancer cells via the PERK/ATF4/ LAMP3-arm of the unfolded protein response. Breast Cancer Res. 2013;15:R2.

49. Pan $Y X$, Chen $H$, Thiaville MM, Kilberg MS. Activation of the ATF3 gene through a co-ordinated amino acid-sensing response programme that controls transcriptional regulation of responsive genes following amino acid limitation. Biochem J. 2007:401:299-307.

50. López A, Lorente JA, Steingrub J, Bakker J, McLuckie A, Willatts S, et al. Multiple-center, randomized, placebo-controlled, double-blind study of the nitric oxide synthase inhibitor 546C88: effect on survival in patients with septic shock. Crit Care Med. 2004;32:21-30.

\section{Submit your next manuscript to BioMed Central and take full advantage of:}

- Convenient online submission

- Thorough peer review

- No space constraints or color figure charges

- Immediate publication on acceptance

- Inclusion in PubMed, CAS, Scopus and Google Scholar

- Research which is freely available for redistribution 